\title{
Epidermal growth factor and hepatocyte growth factor receptors collaborate to induce multiple biological responses in bovine mammary epithelial cells
}

\author{
P. Accornero, ${ }^{1}$ E. Martignani, S. Miretti, L. Starvaggi Cucuzza, and M. Baratta \\ Department of Veterinary Morphophysiology, University of Torino, 10095, Grugliasco (TO), Italy
}

\section{ABSTRACT}

The aim of this work was to explore whether epidermal growth factor (EGF) and hepatocyte growth factor (HGF) could increase the biological responses of a mammary epithelial cell line of bovine origin when added simultaneously. We also investigated a possible molecular mechanism underlying this cooperation. The development of mammary gland requires several circulating and locally produced hormones. Hepatocyte growth factor and its tyrosine kinase receptor, mesenchymal-epithelial transition factor (MET), are expressed and temporally regulated during mammary development and differentiation. Epidermal growth factor receptor and its ligands have also been implicated in the growth and morphogenesis of the mammary epithelium. Both EGF and HGF seem to exert a morphogenic program in this tissue; therefore, we hypothesized that these cytokines could act cooperatively in bovine mammary epithelial cells. We have already shown that the bovine BME-UV cell line, a nontumorigenic mammary epithelial line, expresses both MET and EGF receptor. Simultaneous treatment with HGF and EGF elicited an increase in proliferation, dispersion, degradation of extracellular matrix, and motility. Following EGF treatment, BME-UV mammary cells exhibited an increase in MET expression at both the mRNA and protein levels. Long-term treatment of BME-UV cells with HGF and EGF together increased the level of activation of the extracellular signal-regulated kinase $1 / 2$ and protein kinase B signaling pathways when compared with HGF or EGF alone. These data outline a possible cooperative role of the EGF and HGF pathways and indicate that cross-talk between their respective receptors may modulate mammary gland development in the cow.

Key words: epidermal growth factor, mesenchymalepithelial transition factor (MET), bovine mammary cell, cooperation

Received October 24, 2008.

Accepted March 22, 2009.

${ }^{1}$ Corresponding author: paolo.accornero@unito.it

\section{INTRODUCTION}

The development of the mammary gland is a highly complex and finely tuned mechanism mediated by multiple cytokines both remotely and locally produced. Endocrine hormones, such as estrogens and growth hormone, have a direct stimulatory effect on mammary epithelial cells and the ability to induce the release of locally produced cytokines. These factors, released by the epithelial and mesenchymal compartments of the gland, activate mesenchymal-epithelial interactions that are essential for the correct development of this organ (Sternlicht et al., 2006; Connor et al., 2007). Many locally produced signals and their receptors have been studied. Among these, 2 well-described tyrosine kinase receptors, the epidermal growth factor receptor (EGFR; Stern, 2003) and mesenchymal-epithelial transition factor (MET; Bottaro et al., 1991), play an important role in the morphogenesis of the mammary gland.

Epidermal growth factor receptor activates multiple intracellular pathways that are often associated with cell proliferation and survival. When one of the various epidermal growth factor (EGF)-related ligands activate this receptor, it dimerizes with another EGFR monomer or 1 of 3 other related receptors-ErbB2, ErbB3, or ErbB4. Several EGFR ligands can promote murine mammary development if given exogenously (Troyer and Lee, 2001).

Hepatocyte growth factor (HGF) was originally described as a mitogenic factor for hepatocytes during liver regeneration, but $\mathrm{HGF}$ has a variety of additional biological activities including motogenesis and morphogenesis in cells that express its receptor, MET (Birchmeier et al., 2003). In culture, many epithelial cell lines respond to HGF treatment by increased motility and dispersion (an event known as scatter), hence this cytokine was also named "scatter factor." In collagen matrix, HGF induces the formation of branched tubules from epithelial cells derived from the mammary gland, the kidney, and other organs. Hepatocyte growth factor and MET are expressed and temporally regulated during mammary development and differentiation (Yang et al., 1995; Soriano et al., 1998). In this context, 
mammary fibroblasts produce HGF that is mitogenic, morphogenic, and motogenic for both human and mouse mammary epithelial cells (Brinkmann et al., 1995; Soriano et al., 1995).

We and others have recently demonstrated that MET is expressed in the bovine mammary gland and bovine mammary epithelial cells (Yamaji et al., 2006; Accornero et al., 2007a). We also showed that activation of MET by HGF induced activation of the extracellular signal-regulated kinase $1 / 2(\mathbf{E R K 1 / 2})$ and the protein kinase B (AKT) pathways and elicited numerous biological events such as proliferation, scatter, and invasion (Accornero et al., 2007b). Similarly, we showed that BME-UV cells also express EGFR and that its stimulation with EGF activated ERK1/2 and AKT but had minimal effects on proliferation, scatter, and invasion.

Many studies have demonstrated multiple mechanisms of collaboration between EGFR and MET. Primary attention has been placed on this interaction in cell lines derived from tumors (Ramos-Nino et al., 2003), whereas limited data are available on cells obtained from nontumorigenic tissues (Moriuchi et al., 2001) and, to our knowledge, no studies have demonstrated collaborative events between EGF and HGF in normal bovine mammary epithelial cells.

Because MET and EGFR are simultaneously expressed and play an important role during mammary development, we investigated whether there was a cooperative effect between these receptors in cultured bovine mammary epithelial cells.

\section{MATERIALS AND METHODS}

\section{Materials, Cells, and Antibodies}

All reagents, unless specified, were from SigmaAldrich (St. Louis, MO), as was the protease inhibitor cocktail; recombinant human HGF and EGF were from Immunotools (Friesoythe, Germany); NucleoSpin RNA II was from Macherey-Nagel (Duren, Germany); Bio-Rad iScript cDNA kit, iQ SYBR Green Supermix, and DC Protein Assay were from Bio-Rad Laboratories (Hercules, CA); Hybond-ECL nitrocellulose membrane and Hyperfilm ECL were from GE Healthcare Bio-Sciences (Piscataway, NJ); Super Signal West Pico Chemiluminescent Substrate was from Pierce (Rockford, IL); Transwell polycarbonate membranes were from Corning-Costar (Lowell, MA); Matrigel Basement Membrane Matrix was from BD Biosciences (Bedford, MA); the programmable real-time thermal cycler (Model Mini-Opticon) was from MJ Research Inc. (Watertown, MA); the Leica AF6000 LX inverted microscope, the DFC350FX digital camera, and the
Leica LAS AF software were from Leica Microsystems (Wetzlar, Germany); and the $\mathrm{CO}_{2}$ microscope cage incubator was from Okolab (Naples, Italy).

The BME-UV bovine mammary epithelial cell line was kindly provided by I. Politis (Agricultural University of Athens, Athens, Greece). The BME-UV cells were established from bovine primary epithelial cells and express functional markers such as microvilli and desmosomes and biochemical markers of mammary epithelial cells such as a repertoire of cytokeratins (Zavizion et al., 1996). The BME-UV cells were grown in Dulbecco's modified Eagle's medium high glucose (DMEM), supplemented with $10 \%$ fetal bovine serum (Euroclone, Pero, Italy) at $37^{\circ} \mathrm{C}$ in a $5 \% \mathrm{CO}_{2}$-water-saturated atmosphere. Cells were routinely passaged every 2 to 3 d by washing with PBS followed by trypsinization. The proliferation, scatter, and invasion assays were performed by adding the indicated cytokines to the growth medium (DMEM + fetal bovine serum) because in the absence of serum, cells progressively lost viability and did not respond to these stimuli. For Western blots and real-time PCR, cells were serum-starved for $24 \mathrm{~h}$ in DMEM with no serum in the presence of $0.2 \%$ BSA, and then the indicated cytokines were added for the specified times. In the experiments performed to evaluate MET and EGFR expression, serum starvation was necessary to suppress the transcriptional effects of all growth factors present in serum. To analyze the effects of EGF and HGF on signal transduction serum starvation was required to lower the basal rate of phosphorylation of ERK1/2 and AKT otherwise elicited by the variety of growth factors present in the serum.

The specific reactivity of anti-MET and anti-EGFR antibodies has been previously demonstrated (Accornero et al., 2007b). Anti-MET mouse monoclonal antibody was from Zymed (South San Francisco, CA); anti-EGFR rabbit polyclonal antibody was from Santa Cruz Biotechnology (Santa Cruz, CA); anti- $\alpha$-tubulin and anti-phospho-ERK 1/2 mouse monoclonal antibodies were from Sigma-Aldrich (St. Louis, MO); antiphospho-AKT (ser-473) mouse monoclonal was from Upstate (Temecula, CA), and anti-ERK 1/2 rabbit polyclonal and anti-AKT rabbit polyclonal antibodies were from Cell Signaling Technologies (Danvers, MA).

\section{Cell Proliferation Assay}

The BME-UV cells were seeded in 6-well plates at a density of $2 \times 10^{5}$ cells per well and allowed to grow. After $24 \mathrm{~h}$, the medium was replaced with fresh medium with serum containing the indicated cytokines. After 36 $\mathrm{h}$, cells were detached by trypsinization and counted on Burker chambers. Nonviable, Trypan blue-positive cells 
were not considered. Cell numbers were expressed as a percentage of the untreated (control) well's count.

\section{Scatter Assay}

The BME-UV cells were seeded in 6-well plates at a density of $3 \times 10^{4}$ cells/well and cultured until they formed tightly packed colonies (about $48 \mathrm{~h}$ ). The medium was replaced with medium containing serum and the indicated cytokines and cells were photographed using a Leica AF6000 LX inverted microscope equipped with a fully automated stage controlled by Leica LAS AF software, a Leica DFC350FX digital camera, and a $\mathrm{CO}_{2}$ incubator. Images were taken every $3 \mathrm{~min}$ for $10 \mathrm{~h}$ and then exported as AVI videos at 20 frames per second. Text was added to the video using the free video editor software Wax 2.0 (http://www.debugmode.com/ $\operatorname{wax} /)$.

\section{In Vitro Invasion Assay}

Invasiveness was examined by using the membrane invasion culture system (Transwell polycarbonate membranes; $6.5 \mathrm{~mm}$ diameter, $8-\mu \mathrm{m}$ pore size). The BMEUV cells were trypsinized and $3 \times 10^{4}$ cells in $200 \mu \mathrm{L}$ of medium with serum were seeded onto the upper well of Transwells previously coated with $25 \mu \mathrm{g}$ of Matrigel basement membrane matrix. The lower well was filled with $800 \mu \mathrm{L}$ of complete medium and the indicated cytokines were added. After $48 \mathrm{~h}$, the noninvasive cells on the upper surface of the membrane were removed with a cotton swab. Cells that solubilized the Matrigel, passed through the $8-\mu \mathrm{m}$ pores of the Transwell, and attached to the lower surface of the membrane were fixed with $11 \%$ glutaraldehyde, stained with crystal violet, and photographed. For quantification, the Transwell membranes were detached and solubilized in $10 \%$ acetic acid water solution and the intensity of the colored solution was quantified by spectrophotometric analysis at 595 $\mathrm{nm}$. Intensities were expressed as a percentage of the untreated (control) Transwell's intensity.

\section{Western Blot Analysis}

Cells were plated in 6-well plate and cultured until they reached $50 \%$ confluence. Cells were incubated for $24 \mathrm{~h}$ in medium without serum containing $0.2 \%$ BSA and, following another change of medium, the indicated cytokines were added and incubated for $16 \mathrm{~h}$. Cells were washed with ice-cold PBS, lysed, and scraped in lysis buffer $[20 \mathrm{mmol}$ of Tris/L, $\mathrm{pH} 7.5 ; 150 \mathrm{mmol}$ of $\mathrm{NaCl} / \mathrm{L} ; 1 \mathrm{mmol}$ of EDTA/L; $1 \mathrm{mmol}$ of ethylene glycol tetraacetic acid (EGTA)/L; 1\% Triton X-100; $1 \mathrm{mmol}$ of h-glycerolphosphate/L] with $1 \%$ protease inhibitor cocktail (Sigma-Aldrich) and $1 \mathrm{mmol}$ of sodium-orthovanadate/L. Protein lysates were cleared of cellular debris by centrifugation at $4^{\circ} \mathrm{C}$ at $12,000 \times$ $g$ for 10 min, quantified using the DC Protein Assay, resolved in 10\% SDS-PAGE gels, and transferred to Hybond-C Extra nitrocellulose membranes. After the transfer of proteins, the membrane was blocked at room temperature for $2 \mathrm{~h}$ with Tris-buffered saline (TBS, $10 \mathrm{~m} M$ Tris and $150 \mathrm{~m} M \mathrm{NaCl}, \mathrm{pH}$ 7.4) containing $10 \% \mathrm{BSA}$ and then incubated overnight at $4^{\circ} \mathrm{C}$ with the appropriate primary antibodies. The membranes were washed 6 times for $5 \mathrm{~min}$ each in TBS-Tween and then incubated for $1 \mathrm{~h}$ at room temperature with horseradish peroxidase conjugated secondary antibodies. The membranes were again washed several times in TBS-Tween and incubated with Super Signal West Pico enhanced chemiluminescence peroxidase substrate for $5 \mathrm{~min}$ at room temperature. The proteins were visualized by exposing the membrane to a Hyperfilm ECL autoradiography film.

\section{Preparation of $m R N A$ and Real-Time PCR}

Cells were plated in 6-well plates and cultured until they reached $50 \%$ confluence. Cells were serum-starved for $24 \mathrm{~h}$ in medium without serum containing $0.2 \% \mathrm{BSA}$ and then, following another change of medium, the indicated cytokines were added and incubated for $16 \mathrm{~h}$. Total RNA was extracted with a NucleoSpin RNA II kit following the manufacturer's recommended protocol. One microgram of total RNA was reverse transcribed with an iScript cDNA kit following the manufacturer's instructions. Real-time PCR was used to measure the quantity of MET relative to the quantity of hypoxanthine phosphoribosyl-transferase 1(HPRT-1) mRNA. The HPRT-1 gene was used as a normalization gene to correct for RNA concentration and reverse transcription efficiency. Diluted cDNA (1:5 and 1:50) were used for real-time PCR amplification using iQ SYBR Green Supermix. Primers for bovine MET were: forward 5'-CGC TAT GAT GCA AGA GTA CAC A-3', reverse 5'-TTA GGA AAC TGG TCT TCT GGA-3' (efficiency 1.79); primers for HPRT-1 were: forward 5'-TGA CAC TGG CAA AAC AAT GCA-3', reverse 5'-GGT CCT TTT CAC CAG CAA GCT-3' (efficiency 1.87). Real-time PCR parameters were: cycle $1,95^{\circ} \mathrm{C}$ for $3 \mathrm{~min}$; cycle 2 , $95^{\circ} \mathrm{C}$ for $60 \mathrm{~s}, 60^{\circ} \mathrm{C}$ for $30 \mathrm{~s}$ for 40 cycles. The $\Delta\left(\Delta \mathrm{C}_{\mathrm{T}}\right)$ method was used to analyze the data as described by Livak and Schmittgen, (2001).

\section{Statistical Analysis}

Each experiment was repeated 3 times independently and in each experiment each treatment was performed 
with 2 to 3 replicates. Experimental data are presented as mean \pm standard deviation. Statistical differences between treatments were calculated with one-way ANOVA using the Statgraphics package (STSC Inc., Rockville, MD). When significant differences were found, means were compared by Scheffe's F test.

\section{RESULTS}

\section{Simultaneous Addition of HGF and EGF Increases Proliferation of BME-UV Bovine Mammary Epithelial Cells}

We previously reported that BME-UV bovine mammary cells express both EGFR and MET and that these cells respond to $\mathrm{HGF}$ or, to a lesser extent, EGF addition by increased proliferation (Accornero et al., $2007 \mathrm{~b}$ ). Thus, we verified that simultaneous addition of HGF + EGF promoted proliferation in this cell line beyond that observed with HGF or EGF alone. Cells were plated and cultured for $36 \mathrm{~h}$ in standard medium without (control), with HGF, with EGF, or with HGF + EGF (10 ng/mL each). To evaluate differences between the treatments, cells were trypsinized, stained with Trypan blue (to exclude nonviable cells) and counted. Quantities were expressed as a percentage of the control group's count. The HGF + EGF treatment had the strongest potential to induce cell proliferation $(245 \%, P<0.05)$ compared with EGF $(197 \%)$ or HGF (205\%; Figure 1).

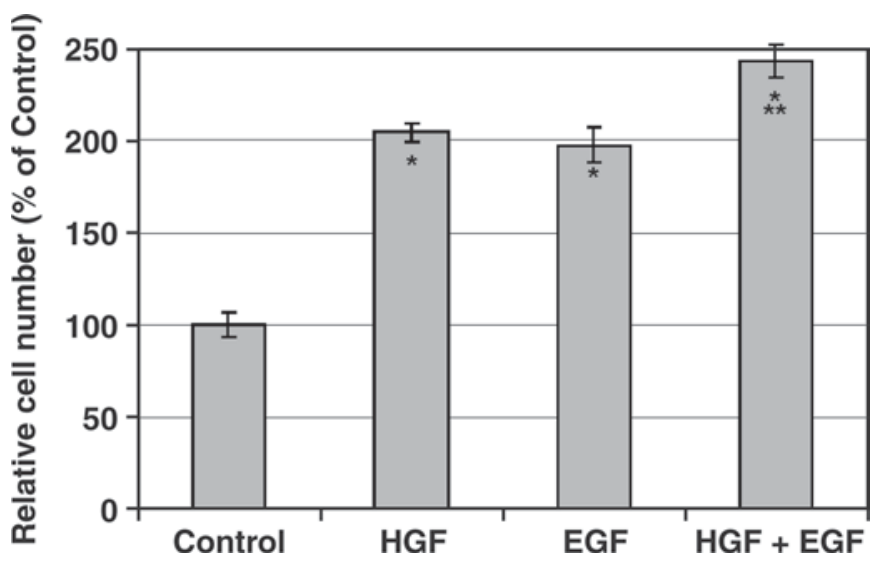

Figure 1. Effect of epidermal growth factor (EGF) and hepatocyte growth factor (HGF) treatment on BME-UV mammary cell proliferation. The BME-UV cells were cultivated for $36 \mathrm{~h}$ with no cytokines (control), $10 \mathrm{ng}$ of $\mathrm{HGF} / \mathrm{mL}, 10 \mathrm{ng}$ of $\mathrm{EGF} / \mathrm{mL}$, or $10 \mathrm{ng}$ of $\mathrm{EGF} / \mathrm{mL}$ plus $10 \mathrm{ng}$ of $\mathrm{HGF} / \mathrm{mL}$ and then counted. Each bar shows quantification, in percentage relative to the untreated control. Graph bars represent the mean \pm standard deviation of 3 experiments with 2 replicates per each treatment. ${ }^{*} P<0.05$ vs. control; ${ }^{* *} P<0.05$ vs. HGF.

\section{Enhanced Motility and Dispersion (Scatter) of BME-UV Cells after Stimulation with HGF and EGF}

We reported previously that BME-UV cells exhibited a scatter response to HGF but not EGF treatment. Thus, we tested whether HGF and EGF could synergize to evoke scatter in BME-UV cells. To determine a possible collaboration between EGF and HGF in this assay, we reduced the amount of HGF added to the medium to $0.15 \mathrm{ng}$ of $\mathrm{HGF} / \mathrm{mL}$ (Figure 2; HGF), because of the fact that HGF alone, used at high concentrations (10 ng of $\mathrm{HGF} / \mathrm{mL}$ ), induced complete dissociation of cells (Accornero et al., 2007b). At $0.15 \mathrm{ng}$ of HGF/ $\mathrm{mL}$, HGF did not evoke scatter, and cells were indistinguishable from untreated control (Figure 2, control). Cells treated with EGF (10 ng of EGF/mL) also never completely dissociated [Figure 2, EGF; and Accornero et al., (2007b)]. Interestingly, HGF + EGF promoted cell detachment and motility to a much higher degree (Figure 2, HGF + EGF; and supplementary video, available online: http://jds.fass.org/content/vol92/issue8/).

\section{EGF and HGF Simultaneous Addition Promotes Increased Invasion}

We previously showed that HGF promoted invasion in BME-UV cells, whereas EGF had a low invasive potential. We therefore tested whether HGF $(10 \mathrm{ng} / \mathrm{mL})$ and EGF (10 ng/mL) could synergize in this assay: untreated and EGF-treated cells did not invade (Figure 3A, control and EGF), whereas HGF induced cells to dissolve the matrix and to pass through the pores of the Transwells. The BME-UV cells stimulated concurrently with HGF and EGF were significantly more invasive (Figure 3A, HGF + EGF). Quantification of cells that passed through the Transwells confirmed that HGF + EGF had a synergistic effect on invasion (Figure 3B; $P$ $<0.05)$.

\section{EGF Increases Expression of MET Protein and $m R N A$}

We analyzed possible variations in the expression levels of MET and EGFR in BME-UV cells after induction with HGF or EGF. For this purpose, cells were serum-starved for $24 \mathrm{~h}$ and then either left unstimulated (control) or treated for $16 \mathrm{~h}$ with HGF $(10 \mathrm{ng} / \mathrm{mL})$, EGF $(10 \mathrm{ng} / \mathrm{mL})$ and HGF plus EGF. Cells were lysed and $20 \mu \mathrm{g}$ of total protein cell extracts were separated by SDS-PAGE and analyzed by immunoblotting for the expression of MET and EGFR. Tubulin immunoblotting was used to confirm that equal amounts of protein 
had been correctly loaded. In EGF-treated cells, we observed an increase in the expression of MET when compared with control or HGF-treated cells (Figure 4A). Treatment with EGF also dramatically lowered the expression of its own receptor, a well-described mechanism that involves internalization and degradation (Sorkin and von Zastrow, 2002). Densitometric analysis of Western blots confirmed an effect on MET and EGFR expression in EGF and HGF + EGF treated cells (Figure 4B; $P<0.05$ ). We then analyzed whether the increased expression level of MET after EGFR activation could also be observed at the mRNA level. Cells were serum-starved for $24 \mathrm{~h}$ and stimulated with HGF, EGF, or HGF plus EGF for $16 \mathrm{~h}$. Total RNA was extracted and real-time PCR was used to measure the relative levels of MET mRNA expression after normalization with HPRT mRNA (Figure 4C). In agreement with the data obtained by Western blot analysis, we observed a 2- to 5-fold increase in MET mRNA level $($ mean $=2.96$ times; $P<0.05)$ in EGF treated samples compared with the level of untreated (control) cells. Treatment with HGF only slightly stimulated MET expression (1.2- to 1.4-fold vs. control, mean $=1.34$ ).

\section{Prolonged Treatment of BME-UV Cells with HGF and EGF Enhances the Activation of ERK1/2 and AKT}

We have previously demonstrated that both HGF and EGF activate the ERK $1 / 2$ and the AKT pathways in BME-UV cells and that deactivation via dephosphorylation of both effectors occurs rapidly (Accornero et al., 2007b). The increase in proliferation (36 h), scatter $(10 \mathrm{~h})$ and invasion $(48 \mathrm{~h})$ mediated by EGF plus HGF is the result of chronic activation of multiple intracellular signaling pathways. Thus, we verified whether HGF and EGF, when added simultaneously, could enhance the activation of the ERK1/2 and AKT pathways even after a long incubation time. To lower the basal rate of phosphorylation of ERK1/2 and AKT cells were serumstarved for $24 \mathrm{~h}$ and then left unstimulated (control) or stimulated with HGF $(10 \mathrm{ng} / \mathrm{mL})$, EGF $(10 \mathrm{ng} / \mathrm{mL})$, or HGF + EGF $(\mathrm{H}+\mathrm{E})$ for 1,4 , or $8 \mathrm{~h}$. Twenty micrograms of total cell protein extracts were analyzed by immunoblotting with specific ERK1/2 and AKT antiphospho antibodies. Total ERK1/2 and AKT were used as loading controls. The rate of activation of ERK1/2 and AKT in untreated cells was low but increased after HGF treatment. Addition of EGF provided a further increase of ERK1/2, but not AKT phosphorylation compared with HGF. Interestingly, the HGF + EGF treatment enhanced the activation of both ERK1/2 and AKT at all time intervals (Figure 5).
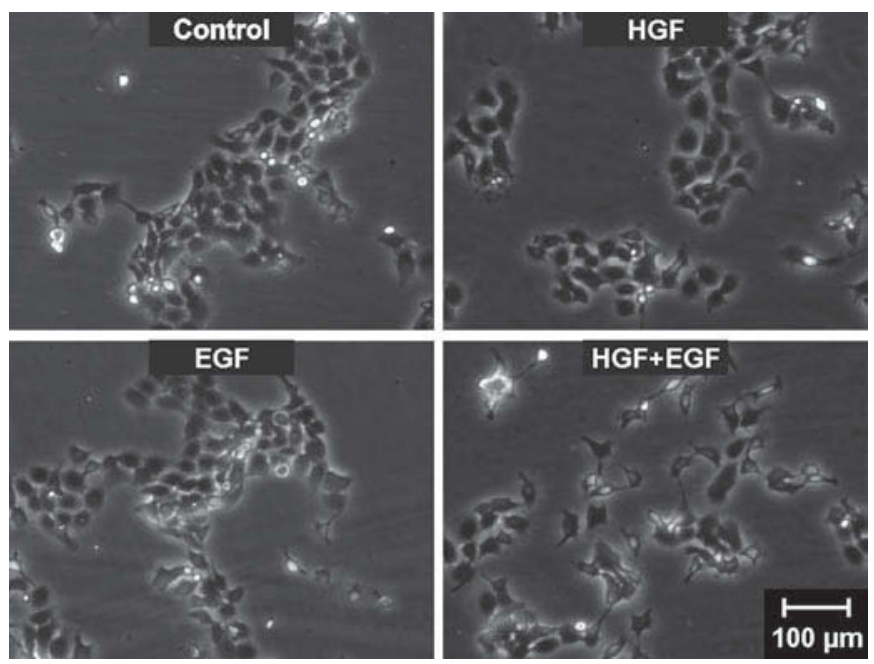

Figure 2. Effect of hepatocyte growth factor (HGF), epidermal growth factor (EGF), and HGF + EGF treatments on bovine mammary cell scatter. The BME-UV cells were seeded at low density and cultured until they formed tightly packed clusters. Subsequently, $0.15 \mathrm{ng}$ of $\mathrm{HGF} / \mathrm{mL}, 10 \mathrm{ng}$ of $\mathrm{EGF} / \mathrm{mL}$, or $10 \mathrm{ng}$ of $\mathrm{EGF} / \mathrm{mL}$ plus $0.15 \mathrm{ng}$ of $\mathrm{HGF} / \mathrm{mL}$ were added to the culture medium. After $10 \mathrm{~h}$, cells were photographed on a Leica DMI6000B inverted microscope at 50× magnification. The scatter assay was repeated 3 times with similar results. Microphotographs were acquired every $3 \mathrm{~min}$ for $10 \mathrm{~h}$ and assembled to a 20 -frame per second video. Supplementary video available online: http://jds.fass.org/content/vol92/issue8/.

\section{DISCUSSION}

In this study, we determined that MET and EGFR collaborate in many biological responses of BME-UV bovine mammary cells. The mammary gland is an organ in which a large number of remodeling events follow one another during the development and the reproductive cycle of the animal. After puberty and during pregnancy, proliferation and morphogenesis of the mammary epithelium results in the development of an extended network of ducts and alveoli. Branching morphogenesis and lobulo-alveolar differentiation of the mammary gland are regulated by a complex interplay of systemic hormonal signals and local factors (Imagawa et al., 2002). In these processes, mesenchymal-epithelial as well as epithelial-mesenchymal cell interactions play an important role. Paracrine factors are produced from the epithelial compartment of the gland (luminal and myoepithelial cells) and from the surrounding mesenchyma, mainly adipocytes and fibroblasts. Among these factors, EGF and HGF play an important role for the correct development of the gland (Yang et al., 1995; Troyer and Lee, 2001).

Epidermal growth factor acts by activating its receptor EGFR and it is reported to have an important role both in the epithelial and luminal compartments (Luetteke et al., 1999). In particular, one of the EGFR 

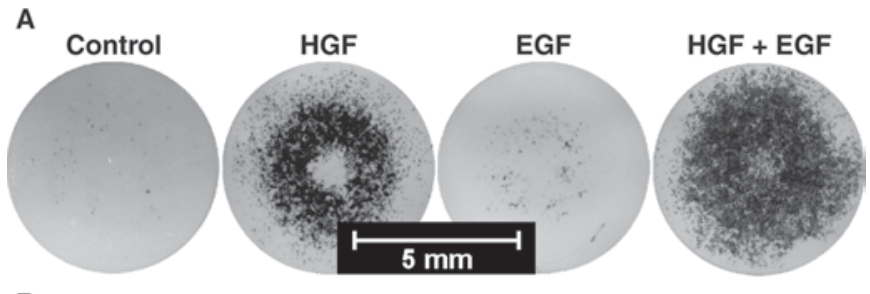

B

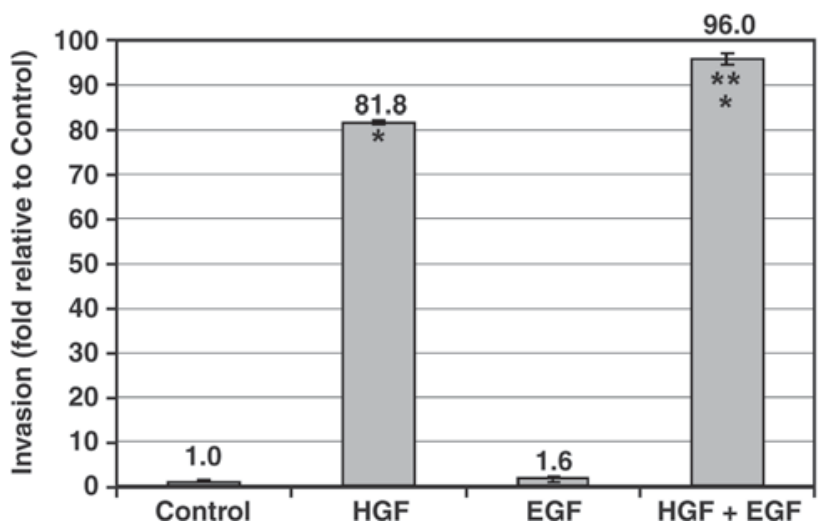

Figure 3. Effect of hepatocyte growth factor (HGF), epidermal growth factor (EGF), and HGF + EGF treatments on BME-UV cell invasion. Cells were seeded on Matrigel-coated Transwells and then either left untreated (control) or treated with $10 \mathrm{ng}$ of $\mathrm{HGF} / \mathrm{mL}, 10 \mathrm{ng}$ of $\mathrm{EGF} / \mathrm{mL}$, or $10 \mathrm{ng}$ of $\mathrm{EGF} / \mathrm{mL}$ plus $10 \mathrm{ng}$ of $\mathrm{HGF} / \mathrm{mL}$. A) Pictures of Transwells; B) spectrophotometric quantification of the Transwells in panel A. Untreated Transwells were used as control. Increase in cell invasion is expressed as fold increase in treated cells compared with control, which was assigned a value of 1 . Pictures are representative of 3 different experiments with 2 replicates each; bar graphs are the means \pm standard deviation of the same experiments. ${ }^{*} P<0.05$ vs. control; ${ }^{* *} P<0.05$ vs. HGF.

multiple ligands, amphiregulin, which is secreted by mammary epithelial cells that express estrogen receptor $\alpha$, plays a fundamental role to promote the morphogenesis of the gland by activating EGFR in the stromal compartment. Interestingly, EGFR is also expressed in murine and bovine mammary epithelial cells, and therefore there might be a signaling function for this receptor in the epithelial compartment as well (Ciarloni et al., 2007; Connor et al., 2007).

Hepatocyte growth factor, on the other hand, is secreted from mesenchymal/stromal cells and acts on adjacent epithelial cells by activating the MET receptor. Hepatocyte growth factor has been described as a possible mediator of the morphogenic program in many cell lines of different origin including mammary cells (Soriano et al., 1995).

Recent evidence has outlined mechanisms of interaction between MET and EGFR that ultimately drive some biological and pathological processes including wound healing and cancer (Yamamoto et al., 2006; Xu and $\mathrm{Yu}, 2007)$. We have previously shown that BME-UV mammary cells express MET and EGFR (Accornero
A

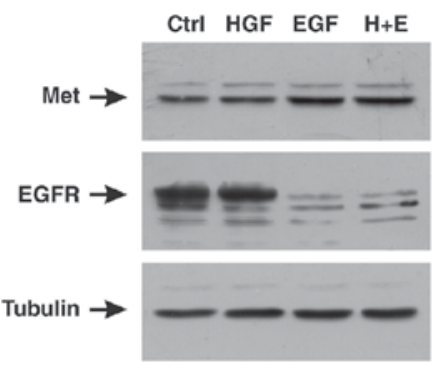

B

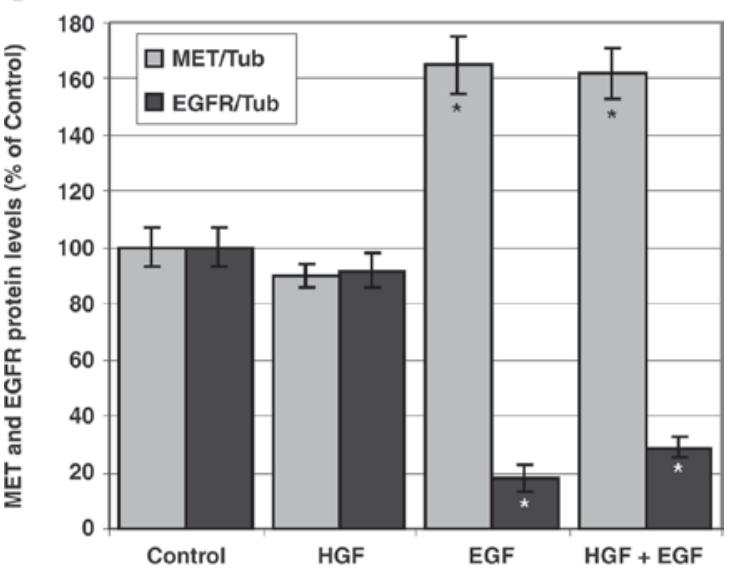

C

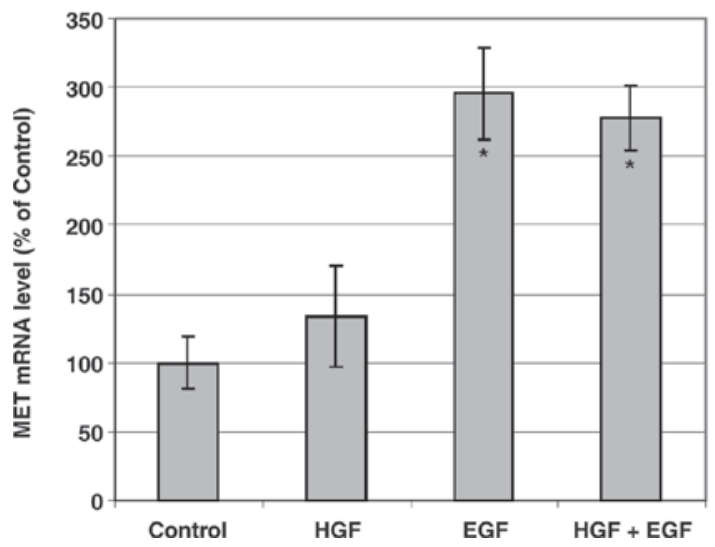

Figure 4. Effect of hepatocyte growth factor (HGF), epidermal growth factor (EGF), and HGF + EGF treatments on mesenchymalepithelial transition factor (MET; the HGF receptor) and EGF receptor (EGFR) protein levels and on MET mRNA expression. The BMEUV cells were serum-starved for $24 \mathrm{~h}$ and then left untreated (control) or treated for $16 \mathrm{~h}$ with $10 \mathrm{ng}$ of $\mathrm{HGF} / \mathrm{mL}, 10 \mathrm{ng}$ of $\mathrm{EGF} / \mathrm{mL}$, or $10 \mathrm{ng}$ of $\mathrm{HGF} / \mathrm{mL}$ plus $10 \mathrm{ng}$ of $\mathrm{EGF} / \mathrm{mL}$ before being lysed for total protein or mRNA extraction. A) MET (140 kDa), EGFR (170 kDa), and tubulin (Tub; $50 \mathrm{kDa}$ ) proteins were detected with specific antibodies; tubulin was used as a total protein loading control. Pictures are representative of 3 different Western blot analyses. B) The relative intensity of MET or EGFR was normalized to total value of tubulin determined by densitometric analysis. Each bar shows quantification as a percentage relative to the untreated control (control). ${ }^{*} P<0.05$ vs. control. C) The MET mRNA level was assessed through quantitative real-time PCR using specific primers that anneal on different exons. Data were normalized to HPRT expression and comparisons among different samples were made using the cycle threshold $\left(\Delta \Delta \mathrm{C}_{\mathrm{T}}\right)$ method; each bar shows quantification as a percentage relative to the untreated control (control). Graph bars represent the mean \pm standard deviation of 3 different experiments with 3 replicates per each treatment. ${ }^{*} P<0.05$ vs. control. 


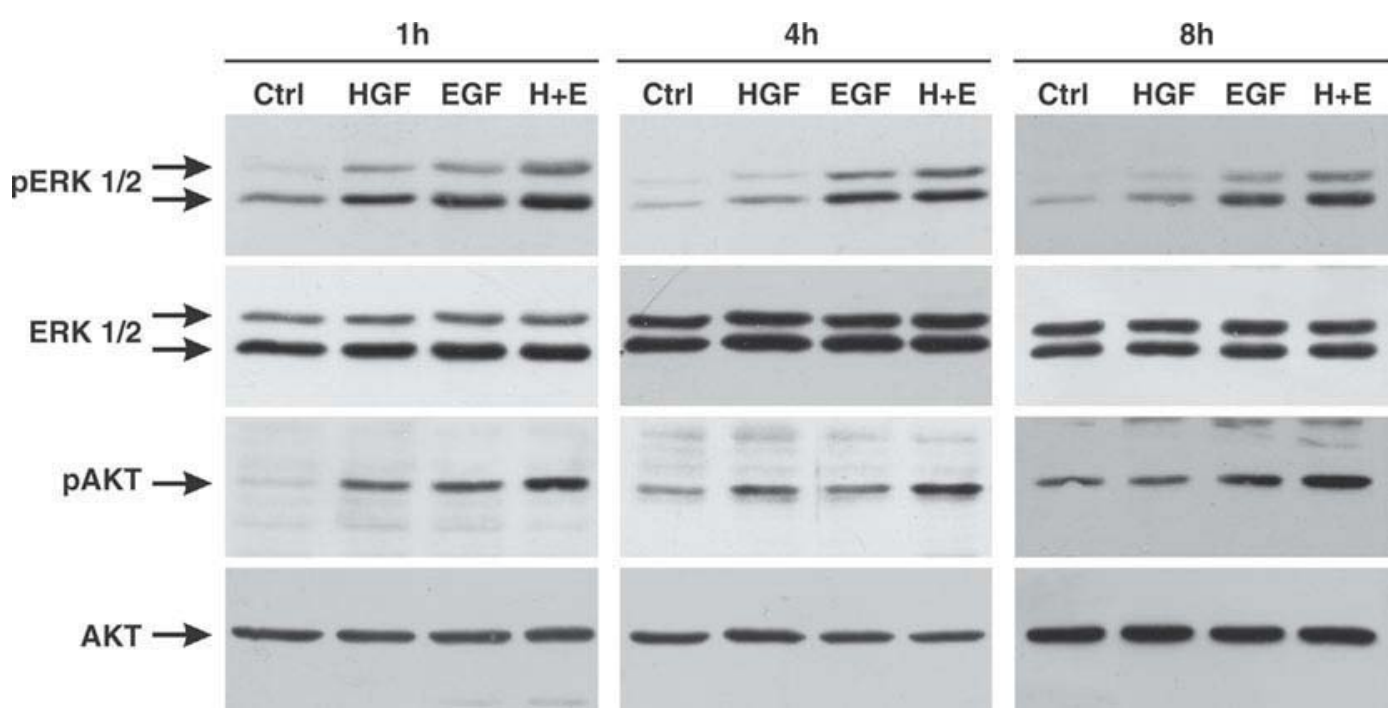

Figure 5. Effect of hepatocyte growth factor (HGF) and epidermal growth factor (EGF) simultaneous treatment on extracellular signalregulated kinase $(\mathrm{ERK})$ and protein kinase B signal (AKT) signal transduction pathways in BME-UV cells. Cells were serum-starved for $24 \mathrm{~h}$ and then either left untreated (control) or treated for $1 \mathrm{~h}, 4 \mathrm{~h}$, or $8 \mathrm{~h}$ with $10 \mathrm{ng}$ of $\mathrm{HGF} / \mathrm{mL}, 10 \mathrm{ng}$ of EGF/mL, or $10 \mathrm{ng}$ of $\mathrm{HGF} / \mathrm{mL}$ plus $10 \mathrm{ng}$ of EGF/mL. Subsequently cells were lysed and protein lysates were immunoblotted. The phosphorylated (p) forms of ERK1/2 (42 and 44 $\mathrm{kDa})$ and AKT $(60 \mathrm{kDa})$ proteins were detected with specific antibodies. The same membranes were then stripped and reprobed against total ERK1/2 and AKT. Pictures shown are representative of 3 different Western blot analyses.

et al., 2007b) and that both receptors, if stimulated by their respective ligands, activate the ERK1/2 and the AKT pathways. We also showed that HGF, but not EGF, induced multiple morphogenic responses like scatter and invasion in this cell line. Because mammary epithelial cells are exposed to both EGF and HGF during the development of the gland, we postulated that these 2 growth factors may exert cooperative effects on the phenotypic modulation of mammary cells.

Many mammary epithelial cell lines have been shown to respond with proliferation when treated with different growth factors, including HGF or EGF. We first observed that BME-UV cells treated with HGF and EGF together responded with increased proliferation compared with the treatment with each cytokine alone. Cooperative mitogenic effects of HGF plus either EGF or TGF- $\alpha$ have also been reported in cultured rat hepatocytes, implying that cooperativity may exist between these growth factor/receptor pathways (Jo et al., 2000; Moriuchi et al., 2001).

Scatter is a phenomenon documented in many cell types, in which cohesive cell colonies spread out, separate into individual cells and acquire a fibroblastic migratory phenotype. We already demonstrated that HGF, but not EGF, had a strong scatter-inducing ability on BME-UV cells. To test if HGF and EGF collaborated in this assay we lowered HGF concentrations to preclude mammary cells to scatter by the mean of this cytokine alone. The data available on the local active concentrations of all paracrine factors that mediate morphogenesis in the mammary gland are still poor. In fact, the biological availability of many cytokines is modulated, in-vivo, by multiple factors including, for example, the presence of enzymes required for the local activation of these cytokines (TACE/ADAM17 for EGF ligands and urokinase plasminogen activator or tissue plasminogen activator for HGF) or the presence of the basement membrane and multiple layers of cells that may modulate the diffusion of these hormones (Birchmeier and Gherardi, 1998; Harris et al., 2003). Under our experimental conditions (reduced HGF concentration) we showed that EGF collaborates with HGF to induce scatter in BME-UV cells. Because scatter is a necessary event that occurs before several morphogenic processes that are also active during mammary gland development, we speculate that HGF and EGF might collaborate to evoke scatter in this context.

In this work, we also showed that invasion is increased in the presence of EGF and HGF together. During embryogenesis, in a physiological context, invasive growth is involved in complex developmental events including morphogenesis of epithelia, angiogenesis, nerve sprouting, and myoblast migration (Birchmeier and Gherardi, 1998). This feature is of great importance in the developing mammary gland. In this context, cells that colonize the gland and create the new tubular structures of this organ, degrade the surrounding extracellular matrix, proliferate and move to create new tissue.

The BME-UV cell line stimulated with HGF responded with an enormous increase in the ability to 
degrade the extracellular matrix (matrigel) and move through Transwell pores. Interestingly, under the same conditions EGF had a very mild capacity to induce invasion whereas EGF and HGF when added together induced invasion synergistically. Other authors have demonstrated a similar collaborative role for these growth factors in ovarian cancer cells (Zhou et al., 2007).

To uncover a possible molecular mechanism of collaboration between EGFR and MET, we decided to examine if EGF or HGF could influence the other receptor's signaling pathway. Multiple mechanisms of cooperation between MET and EGFR have been described, among which are trans-phosphorylation and ligand/receptor upregulation (Ramos-Nino et al., 2003; Spix et al., 2007). We did not detect any trans-phosphorylation event between EGFR and MET in BMEUV cells treated with EGF or HGF (data not shown). We observed an increase in MET protein and mRNA in EGF treated cells while EGFR expression, strongly down-modulated by EGF addition, was not altered by HGF. Result supports the concept that MET upregulation in response to EGF is a one-way signaling mode of this cell line.

Activation of MET and EGFR by ligation of active HGF or EGF allows the recruitment of numerous signaling mediators such as phosphoinositide 3-kinase and Src tyrosine kinase, as well as several adaptor proteins such as Grb2 (which activates the ERK pathway), Gab1, Shc, and c-Cbl. We previously showed that HGF or EGF addition to BME-UV cells induced activation of the ERK1/2 and AKT pathways (Accornero et al., 2007b). In this context, EGFR may contribute to MET signaling by amplification of common downstream pathways, thereby increasing the potential of MET to induce long-term morphogenic-promoting effects including proliferation, scatter, and invasion. Thus, we verified possible consequences of the simultaneous treatment of BME-UV cells on the activation persistency of the ERK1/2 and AKT pathways. Cells stimulated concurrently with HGF and EGF for 1, 4, and $8 \mathrm{~h}$ showed an increase in the phosphorylation of these effectors compared with HGF or EGF alone. This type of cooperative event has not been described in bovine mammary cells, but has been already demonstrated in another context. During liver regeneration, EGFR and MET were shown to collaborate through an additive effect on growth by concurrent activation of the Ras/ERK pathway in rat hepatocytes (Moriuchi et al., 2001).

In summary, in this work we have verified that HGF and EGF collaborate in eliciting several biological responses of bovine mammary epithelial cells and we propose a possible molecular mechanism underlying this collaboration. The effects described in this work show how HGF and EGF, acting together through their respective receptors, MET and EGFR, promoted an increase in proliferation, scatter, and invasion. This study also provides evidence for a mechanism of communication between the EGFR and MET pathways. Finally, we showed that activation of both EGFR and MET signaling cascades can result in cooperative activation of downstream signaling effectors that may enhance biological outcomes. We propose that HGFdependent MET signaling may be amplified by concurrent activation of the EGFR, which results in increased HGF-induced proliferation, scatter, and invasion in mammary bovine cells. Together, these data suggest that HGF and EGF might be important regulators of morphogenesis and development in bovine mammary gland.

\section{ACKNOWLEDGMENTS}

This work was supported by grants from Piemonte Region A122 and Compagnia di San Paolo 2006.

\section{REFERENCES}

Accornero, P., S. Luvara, A. Favole, E. Macchi, M. Motta, and M. Baratta. 2007a. Biological role of the HGF/MET ligand/receptor couple in bovine mammary epithelial cells. Vet. Res. Commun. 31(Suppl 1):161-164.

Accornero, P., E. Martignani, E. Macchi, and M. Baratta. 2007b. Hepatocyte growth factor exerts multiple biological functions on bovine mammary epithelial cells. J. Dairy Sci. 90:4289-4296.

Birchmeier, C., W. Birchmeier, E. Gherardi, and G. F. Vande Woude. 2003. Met, metastasis, motility and more. Nat. Rev. Mol. Cell Biol. 4:915-925.

Birchmeier, C., and E. Gherardi. 1998. Developmental roles of HGF / $\mathrm{SF}$ and its receptor, the c-Met tyrosine kinase. Trends Cell Biol. 8:404-410

Bottaro, D. P., J. S. Rubin, D. L. Faletto, A. M. Chan, T. E. Kmiecik, G. F. Vande Woude, and S. A. Aaronson. 1991. Identification of the hepatocyte growth factor receptor as the c-met proto-oncogene product. Science 251:802-804.

Brinkmann, V., H. Foroutan, M. Sachs, K. M. Weidner, and W. Birchmeier. 1995. Hepatocyte growth factor/scatter factor induces a variety of tissue-specific morphogenic programs in epithelial cells. J. Cell Biol. 131:1573-1586.

Ciarloni, L., S. Mallepell, and C. Brisken. 2007. Amphiregulin is an essential mediator of estrogen receptor alpha function in mammary gland development. Proc. Natl. Acad. Sci. USA 104:5455-5460.

Connor, E. E., M. J. Meyer, R. W. Li, M. E. Van Amburgh, Y. R. Boisclair, and A. V. Capuco. 2007. Regulation of gene expression in the bovine mammary gland by ovarian steroids. J. Dairy Sci. 90(E Suppl.):E55-E65.

Harris, R. C., E. Chung, and R. J. Coffey. 2003. EGF receptor ligands. Exp. Cell Res. 284:2-13.

Imagawa, W., V. K. Pedchenko, J. Helber, and H. Zhang. 2002. Hormone/growth factor interactions mediating epithelial/stromal communication in mammary gland development and carcinogenesis. J. Steroid Biochem. Mol. Biol. 80:213-230.

Jo, M., D. B. Stolz, J. E. Esplen, K. Dorko, G. K. Michalopoulos, and S. C. Strom. 2000. Cross-talk between epidermal growth factor receptor and c-Met signal pathways in transformed cells. J. Biol. Chem. 275:8806-8811.

Livak, K. J., and T. D. Schmittgen. 2001. Analysis of relative gene expression data using real-time quantitative PCR and the 2(-Delta Delta C(T)) method. Methods 25:402-408. 
Luetteke, N. C., T. H. Qiu, S. E. Fenton, K. L. Troyer, R. F. Riedel, A. Chang, and D. C. Lee. 1999. Targeted inactivation of the EGF and amphiregulin genes reveals distinct roles for EGF receptor ligands in mouse mammary gland development. Development $126: 2739-2750$.

Moriuchi, A., S. Hirono, A. Ido, T. Ochiai, T. Nakama, H. Uto, T. Hori, K. Hayashi, and H. Tsubouchi. 2001. Additive and inhibitory effects of simultaneous treatment with growth factors on DNA synthesis through MAPK pathway and G1 cyclins in rat hepatocytes. Biochem. Biophys. Res. Commun. 280:368-373.

Ramos-Nino, M. E., L. Scapoli, M. Martinelli, S. Land, and B. T. Mossman. 2003. Microarray analysis and RNA silencing link fra1 to cd44 and c-met expression in mesothelioma. Cancer Res. 63:3539-3545.

Soriano, J. V., M. S. Pepper, T. Nakamura, L. Orci, and R. Montesano. 1995. Hepatocyte growth factor stimulates extensive development of branching duct-like structures by cloned mammary gland epithelial cells. J. Cell Sci. 108:413-430.

Soriano, J. V., M. S. Pepper, L. Orci, and R. Montesano. 1998. Roles of hepatocyte growth factor/scatter factor and transforming growth factor- $\beta 1$ in mammary gland ductal morphogenesis. J. Mammary Gland Biol. Neoplasia 3:133-150.

Sorkin, A., and M. von Zastrow. 2002. Signal transduction and endocytosis: Close encounters of many kinds. Nat. Rev. Mol. Cell Biol. 3:600-614.

Spix, J. K., E. Y. Chay, E. R. Block, and J. K. Klarlund. 2007. Hepatocyte growth factor induces epithelial cell motility through transactivation of the epidermal growth factor receptor. Exp. Cell Res. 313:3319-3325.

Stern, D. F. 2003. ErbBs in mammary development. Exp. Cell Res. 284:89-98.

Sternlicht, M. D., H. Kouros-Mehr, P. Lu, and Z. Werb. 2006 Hormonal and local control of mammary branching morphogenesis. Differentiation 74:365-381.
Troyer, K. L., and D. C. Lee. 2001. Regulation of mouse mammary gland development and tumorigenesis by the ERBB signaling network. J. Mammary Gland Biol. Neoplasia 6:7-21.

Xu, K. P., and F. S. Yu. 2007. Cross talk between c-Met and epidermal growth factor receptor during retinal pigment epithelial wound healing. Invest. Ophthalmol. Vis. Sci. 48:2242-2248.

Yamaji, D., K. Kimura, A. Watanabe, Y. Kon, T. Iwanaga, M. M. Soliman, M. M. Ahmed, and M. Saito. 2006. Bovine hepatocyte growth factor and its receptor c-Met: cDNA cloning and expression analysis in the mammary gland. Domest. Anim. Endocrinol. $30: 239-246$

Yamamoto, N., G. Mammadova, R. X. Song, Y. Fukami, and K. Sato. 2006. Tyrosine phosphorylation of p145met mediated by EGFR and $\mathrm{Src}$ is required for serum-independent survival of human bladder carcinoma cells. J. Cell Sci. 119:4623-4633.

Yang, Y., E. Spitzer, D. Meyer, M. Sachs, C. Niemann, G. Hartmann, K. M. Weidner, C. Birchmeier, and W. Birchmeier. 1995. Sequential requirement of hepatocyte growth factor and neuregulin in the morphogenesis and differentiation of the mammary gland. J. Cell Biol. 131:215-226.

Zavizion, B., M. van Duffelen, W. Schaeffer, and I. Politis. 1996 Establishment and characterization of a bovine mammary epithelial cell line with unique properties. In Vitro Cell Dev. Biol. Anim. 32:138-148.

Zhou, H. Y., Y. L. Pon, and A. S. Wong. 2007. Synergistic effects of epidermal growth factor and hepatocyte growth factor on human ovarian cancer cell invasion and migration: Role of extracellular signal-regulated kinase $1 / 2$ and p38 mitogen-activated protein kinase. Endocrinology 148:5195-5208. 